\title{
Life in the Time of COVID-19: a Case Study of Community Health
}

\author{
David Schelly ${ }^{1}$ \\ Received: 26 April 2021 / Revised: 30 June 2021 / Accepted: 2 July 2021 /Published online: 28 July 2021 \\ (C) W. Montague Cobb-NMA Health Institute 2021
}

\begin{abstract}
Introduction This report uses a present day global pandemic as a case study of health inequities that are best understood by considering the role of time and place.

Method I provide a historical overview of Milwaukee, Wisconsin — one of the most segregated cities in the U.S.- to consider prior health disparities and social conditions. I then focus on COVID-19, tracking the monthly census tract distribution of cases for 6 months, including case and mortality data by race and class.

Results As expected, Black and Hispanic majority census tracts are the most affected by COVID-19, with some communities experiencing nearly 1 positive case per 10 residents. In previous years, Blacks and Hispanics provided approximately $27 \%$ and $3 \%$ of the shares of "natural" deaths, respectively; their shares of COVID-19 deaths in the first 6 months of the pandemic were approximately $35 \%$ and $13 \%$. On the contrary, the share of natural deaths for whites was approximately $65 \%$ in previous years and dropped to $47 \%$ for COVID-19 deaths. The average ages of COVID-19 deaths were 72.5 for Blacks, 61.3 for Hispanics, and 79.9 for whites.

Conclusion The disparities in COVID-19 outcomes in Milwaukee cannot be separated from historical forces, including racebased politics that intensified during the Great Migration of African Americans from the Jim Crow South. The paper concludes by returning to the turn of the 19th century with a historical snapshot of Jane Addams, who lived a short distance south, in a time with conspicuous parallels to the COVID-19 crisis.
\end{abstract}

Keywords Health disparities · Pragmatism · Social determinants of health · Social justice

\section{Background}

The theory of fundamental causes $[1,2]$ suggests that inequities in health are best understood by focusing on the social causes that precede the behavioral ones, or the "causes of causes." For example, we have long known that smoking causes poor health, but a range of complex social and environmental factors determine smoking behaviors. Broadly, these factors include "the conditions in which people are born, grow, live, work, and age" [3].

The COVID-19 pandemic was itself a cause of health inequities, as individuals and communities experienced disparate risk of contracting the disease, variable access to treatment, and unequal resources for dealing with the aftermath, both socially and economically [4]. Importantly, the

David Schelly

dschelly@clarkson.edu

1 Occupational Therapy Department, Clarkson University, 8 Clarkson Ave, Potsdam, NY 13699-5882, USA conditions before the arrival of the pandemic must be considered to best understand the consequences of COVID-19. The present paper focuses on one U.S. county to understand health inequities leading up to the pandemic as well as the early spread of the disease.

The year 2020 in the U.S. also included political and racerelated events that are disputed in terms of their causes and consequences, as well as their impact on the spread of COVID-19. I provide a case study of the effects of the pandemic in Milwaukee County, Wisconsin, focusing on health inequities as they form and spread through time and place. The aim is to capture the complex, temporally situated character of early pandemic life in a particular location, including relevant social and political events that create a landscape in which health inequities form and evolve. Instead of focusing on the experiences of individuals, I consider the community from a wider lens, combining census tract and community level data that capture neighborhood effects associated with historic geographic and social conditions, and I track the monthly distribution of COVID-19 cases for 6 months, beginning 1 month after the first presumptive case was identified in Milwaukee County on March 13, 2020. The objective is to 
provide detailed descriptive, spatial, and graphical data that allows the reader to visualize how social conditions relate to the spread of COVID-19.

I begin by providing historical context long before the pandemic, when the American Pragmatists were concentrated at the University of Chicago, and Jane Addams was advocating for disenfranchised immigrant communities from the Hull House. I provide a brief history of conditions in Milwaukee through the 20th century, when immigration and migration patterns were setting the stage for race and class disparities that persist today. Finally, I introduce the COVID-19 data and describe in numbers, graphs, and a qualitative timeline the first 6 months of the situation in Milwaukee County.

$$
* * * * * *
$$

[F]or a time the only symptoms present are those ascribable to sore throat and fever, the first specific signs being undue pallor, moderate compressibility of the pulse, and lassitude. ... Frequently there is oppressive pain referred to the cardiac region or epigastrium. Toward the end the surface of the body is blanched and cold, the temperature is subnormal, and the radial pulse disappears. ( [5], p. 1787)

There were far too many such patients in Milwaukee, with the disease killing as many as $40 \%$, sometimes within 3 days [6]. The disease spread through respiratory droplets, so those living in poorly ventilated, unsanitary, crowded houses experienced elevated risk. The neighborhoods with the highest mortality rates were those with the most immigrants, with the near south side the hardest hit. Germans and Poles had been arriving there for decades, many fleeing the repressive German Empire, and the small houses were in close proximity to a surplus of unskilled manufacturing jobs. The downside was that the neighborhood conditions were abysmal: a putrid sludge of raw sewage flowed into Lake Michigan, where the lake water was pulled back to the taps for drinking; plumbing availability was limited or absent; streets were unpaved, garbage uncollected; and the neighborhoods were generally neglected by the city.

Diphtheria, described above, killed far fewer residents than other diseases, such as tuberculosis, smallpox, typhoid fever, scarlet fever, pneumonia, and dysentery. In the south side neighborhoods, the annual death rate was as high as 25/ 1000 , depending on the year. Compounding their risk of death, the Germans and Poles in Milwaukee were skeptical of public health officials. They often refused to be vaccinated (i.e., for smallpox) or to receive antitoxin (i.e., for diphtheria) or other treatment, and many cases went unreported. Newspapers and public health officials blamed the immigrants for being dirty, citing their alleged cultural disdain for handwashing and soap usage [6].

Such was life in Milwaukee at the turn of the 20th century.

$$
* * * * * *
$$

The near south side neighborhood has since been split by Interstate 94 as it veers south toward Chicago, where in 90 miles the Hull House is visible to the right. It was from there that Jane Addams studied social inequality; the country was nearing the end of what Omram [7] called the "age of receding pandemics," when mortality was declining, and life expectancy-having improved substantially since the "age of pestilence and famine"-was nearing 50. It was rare, still, for people to die from cardiovascular disease and cancer, in part because they rarely lived long enough.

The Hull House research at the time (see [8]) was cutting edge in its focus on the importance of place for understanding inequality, contributing to the "ecological approach" developed by the early Chicago School sociologists [9]. Residents and visiting scholars studied and described the effects of disparate living conditions across the city, including the "wilderness of bad housing and sanitary neglect" that subjected poor immigrants to high rates of death and disease ( [10], p. 12).

In Milwaukee, like elsewhere, conditions began to improve in the 20th century. Manufacturing was booming, and populations were supported with a steady stream of young immigrant workers. The pandemics of the past, as well as an 1886 labor strike that ended with a militia opening fire on over a thousand mostly Polish immigrant workers, had led to a robust Socialist Party in the city (see [11]). In 1910, the country's first Socialist mayor of a large city was elected in Milwaukee, and housing conditions, labor rights, and public health were prioritized. In attempts to improve the old downtown areas, including the Polish flats that were often packed with boarders, the city began annexation efforts to increase the tax base, building roads, and expanding streetcar lines for the commute [12]. At the same time, Milwaukee became a national leader in labor union organization and was labeled one of the country's "healthiest" cities [6]. When the Spanish flu spread in 1918, Milwaukee was spared with a low death rate, in large part because the Department of Health closed schools, bars, and even churches [6].

To this point, Milwaukee was largely comprised of immigrant enclaves, with Germans and European Jews predominantly in the downtown areas to the north of the Menomonee River, and Poles and Serbians to the south [13]. The Germans and English settled on the east side, the Italians in the Third Ward, and the Irish in the suburbs. Greeks and Croatians settled to the near north side. With each wave of immigrants, the newcomers settled in the oldest houses, typically downtown where the factories were concentrated; residents of the older enclaves, having worked in the factories for decades, could afford to buy homes farther away [14]. During World War I, many of the Germans and Jews in the northern downtown bought houses farther from the city, converting their old homes - many built during the Civil War-into apartments 
to rent to Black migrants from the South, who increasingly concentrated in what would be known as "Little Africa." The white landlords let the houses deteriorate, and most incoming Black migrants had little choice, economically and socially, but to settle there $[13,15]$, although the Black population remained relatively small through the 1930 s.

World War I created labor shortages, and labor recruiters throughout the Midwest went to Mexico, where the Mexican Revolution was underway, to recruit workers for agricultural work [16, 17]. In the 1920s, immigration restrictions on Europe and Asia, as well as labor strikes, exacerbated the need for workers, and additional people were recruited from Mexico to work in the local tanneries, meatpacking plants, steel plants, railroads, and the Allis-Chalmers factory, which manufactured gas engines and tractors. The factory had recently moved to a small village west of Milwaukee, quickly transforming the community into West Allis, a manufacturing hub for the entire city. As the factory grew, other manufacturers moved nearby, and many of the Poles from the south and Germans from the east worked and moved there. Many of the Mexican immigrants moved into the old "Polish flats" [18].

The Great Depression brought troubled times for Milwaukee, including labor conflicts and crime. However, it was initially good for the Socialists: With tens of thousands of layoffs, wage cuts, and rampant foreclosures and evictions, Milwaukeeans were sympathetic to critiques of capitalism and receptive to public relief and welfare programs from the state and county, and from the federal government after President Roosevelt was elected in 1932 (see [12]). The New Deal aid funded public park developments and housing projects, including Greendale, an entire housing community southwest of the city [19]. The enthusiasm for the New Deal programs was so strong that Socialists suffered a brief but potentially lasting setback when many Socialists voted Democratic in 1936. At the local level, though, they retained power through World War II and into the 1950s, when several forces led to significant political changes in the city.

The biggest change was in the form of relatively late effects of the Great Migration, when Blacks from the Jim Crow South began migrating in large numbers to northern cities where manufacturing jobs were available and unions were strong $[13,20]$. In Milwaukee, over 13,000 Blacks arrived around World War II, more than doubling the population from the 1930s, and over the following 25 years, the Black population grew by over $700 \%$, settling almost exclusively in the neighborhoods to the north and northwest of the old downtown [13]. For a time, the jobs were plentiful and good: in the 1950 s, for example, a man who had earned $\$ 18$ a month for farm work in the South earned $\$ 58$ in 4 days at A. O. Smith, one of the Milwaukee's many large manufacturing companies [21]. However, the end of the war also brought larger numbers of servicemen, almost all white, back to a city with major housing shortages. The Hispanic population grew, albeit to a much lesser extent, and the new immigrants continued to concentrate in the near south downtown neighborhoods [16].

The incoming migrants included primarily poorly educated workers who were competing for manufacturing jobs and cheap housing. The longtime Socialist mayor continued annexation efforts and public housing initiatives, but the politics were changing, and the newcomers were increasingly seen as a threat to many of the whites in the suburbs who had previously supported the mayor. The old downtown areas were in dire need of repair, and the people there were poor outsiders of color, rapidly growing in number. Increasingly, the whites in the suburbs did not want tax money to pay for urban renewal. At the same time, though, the Black population was gaining power, with the first Black city council member elected in $1956[12,18]$.

Running for a third term in 1956, the Socialist mayornow competing for Democratic votes in an increasingly twoparty system - only narrowly won after rumors were widely circulated that he was advertising on Southern billboards to recruit Black workers to the city and his political base. Meanwhile, the Federal Housing Administration (FHA) policies were incentivizing suburban living [22]. Real estate agents engaged in "blockbusting," where overpriced homes were sold to Black families just within white neighborhoods, and then the white neighbors were told their housing prices would crash so they too would sell. Lending and housing discrimination made it nearly impossible for Blacks to move to the suburbs, increasingly cementing racial lines among neighborhoods [20].

The Socialist mayor won the reelection, but it would be his last term. Fears of Communism were employed to fight against public housing projects, with many people concealing their fears of the new Black population by arguing that public housing itself was "un-American" [20]. Then in 1958, a white police officer shot and killed a young Black man during a traffic stop, falsely claiming he had charged at him with a knife; 2 weeks later, a white jury declared the killing justified [23]. The civil rights movement in Milwaukee was in full force, and racial tensions were extreme.

Throughout the 1960s, the now-conservative mayor and city council, with the exception of the one Black councilwoman, openly resisted civil rights and urban renewal. The councilwoman pushed unsuccessfully for fair housing laws, and the National Association for the Advancement of Colored People (NAACP) pushed against school segregation and employment discrimination, but initially to no avail. The civil rights movement in Milwaukee was fought over decades, militantly at times, with major protests and sit-ins and marches, one involving 200 people from the NAACP Youth Council marching south through the old Polish neighborhood where they encountered thousands of white counterprotesters chanting "we want slaves" and racial slurs, throwing eggs, rocks, bricks, and cherry bombs. Yet it took the killing of Martin Luther King Jr., and the 
passage of the Civil Rights Act (1968), for the mayor to finally pass an open housing ordinance [13].

The 1970s brought a rapid process of deindustrialization in the U.S., and Milwaukee's industrial character began to transform, with many companies increasingly competing with low wage, no union markets in Japan, Korea, and Taiwan [18]. The 1980s saw major bankruptcies of Milwaukee's industrial employers, including Allis-Chalmers, and manufacturing jobs largely disappeared. The manufacturing workforce went from approximately $60 \%$ of workers in the 1950 s to less than a quarter in 1990. The remaining jobs paid less than in previous years: in the 1980s, a machinist made over $\$ 11$ an hour, but in the shopping centers that replaced the plants, clerks made about \$5. Milwaukee became the poster child of the postindustrial landscape.

Black and Hispanic communities in Milwaukee had long experienced over policing that included overt racial profiling and prejudice, but the "war on drugs" in the 1980s led to what can be considered "the New Jim Crow" [24]. These communities were increasingly targeted by police, leading whole segments of populations to be imprisoned, permanently labeled criminals and felons, financially ruined, and stripped of citizenship rights. Milwaukee was especially affected [18].

The 1990s brought the national antiwelfare campaign. In Milwaukee, "Wisconsin Works" was adopted in an effort to discourage aid to the chronically unemployed, including the growing throngs of working and middle class Blacks and Hispanics whose parents had migrated to Milwaukee for its jobs. Desmond [25] describes a man with a disability receiving $\$ 628$ a month from the program, living in north Milwaukee, where his rent-about average in the poorest neighborhoods-was $\$ 550$. Having not been approved for Supplemental Security Income, it did not take long before he was evicted. Eviction continues to be a pervasive problem in Milwaukee [25].

For the poorest segment of Milwaukee's population, the two decades that followed the Clinton era offered little improvement. Black men born in poverty in the 1980s are likely to still live in poverty, even though white men born in similar conditions earn well over twice as much [26]. The result is that the hypersegregated Black neighborhoods in north Milwaukee continue to be associated with "concentrated poverty, pervasive joblessness, plunging incomes, and mass incarceration" ( [26], p. 4). In the near south neighborhoods, the primarily Mexican Hispanic population has continued to grow substantially, nearly tripling in the 1990s alone.

Political dynamics that became apparent during the civil rights era have continued, where the City of Milwaukee, including the Black and Hispanic downtown areas, as well as urban whites along Lake Michigan, are strongly Democratic. The suburbs, where many of the 19th and early 20th century industrial workers moved, lean Republican, and further away from the city, the State of Wisconsin is firmly red [27].
While the county has long been Democratic as a whole, there has been a persistent tension between the suburbs and the downtown areas with regard to taxes and public spending, and that tension culminated in 2002 when Milwaukee's County Executive resigned over controversy about the county pension system, where public employees were being given large taxpayer funded payouts to retire [28]. A special election was organized, and a young Scott Walker was elected in the nonpartisan election. Over the subsequent years, Walker attempted to weaken the county government in various ways, but his attempts to reign in public spending were widely popular among Conservatives. Then in 2010, the Democratic incumbent governor decided unexpectedly not to seek a third term, and the new Democratic frontrunner, the Milwaukee Mayor, was gravely injured in an altercation after the State Fair, trying to respond to a woman's pleas for help only to be beaten with a tire iron [28]. These factors helped Walker win the election in 2010, and for the first time in decades, the Senate and Assembly were strongly Republican. With a background of ongoing dramas and disputes, legal battles, and mass protests around the State Capital, Governor Walker proceeded to eliminate collective bargaining rights, effectively crippling unions in the state [29]. By 2016, Wisconsin flipped to red for the first presidential election since President Reagan's 1984 reelection by voting for Donald Trump (see [30]).

With this background in mind, I now turn to health data in Milwaukee County in the years leading up to 2020, as well as COVID-19 data in the first 6 months of the pandemic.

\section{Method}

I present health data from before 2020 with the expectation that the most disadvantaged tracts prior to the COVID-19 pandemic - Black tracts with low income and educationwill have the most cases and deaths associated with COVID19 , and that white tracts with higher incomes will be the most insulated, followed by Hispanic tracts. ${ }^{1}$

I draw from several sources to discuss social conditions in Milwaukee County, with census tract data for most variables. The aim is not to capture the experiences of individuals, with often complex combinations of identities and histories, but to capture neighborhood effects associated with geographic and historical disadvantage. With populations ranging from 980 to 10,218, Milwaukee County census tracts encompass multiple neighborhoods, but the high levels of segregation coupled

\footnotetext{
${ }^{1}$ I leave out mention of smaller minorities because census tract data do not capture their plight. Native American communities, for example, have long experienced some of the worst outcomes of any group in the country, but because their largest populations are less than $5 \%$ of any census tract in the county, it is beyond the scope of this paper to discuss health inequities in those communities.
} 
with relatively homogenous populations provide for reasonable glimpses of large effects associated with single categories of race and class.

First, the American Community Survey (ACS), the largest and most recent publicly available household survey, provides race and class data by census tract. For the present purposes, the ACS is preferred over the Current Population Survey because the ACS is mandatory, includes institutionalized group quarters, and has higher response rates because of the use of mail and phone surveys. I use ArcGIS 10.7.1 (ESRI, Redlands, CA) to map the distribution of race and class across census tracts, using 5-year estimates from the 2014-2018 ACS to show census tracts that are (a) majority white (alone), Black (alone), and Hispanic, (b) above the median percentage of households living in poverty, and (c) above the median percentage of $25+$ year olds with no high school degree.

Next, I briefly discuss census tract-level life expectancy data from the Centers for Disease Control and Prevention (CDC) U.S. Small-Area Life Expectancy Estimates Project (USALEEP; [31]). USALEEP geocoded residential addresses on death records between 2011 and 2015 (and 2010 for states other than Wisconsin and Maine). Then, using 5-year estimates from the 2011-2015 ACS and adjusting for small population sizes, the study estimated life expectancy at birth for $88.7 \%$ of U.S. census tracts. The study is the smallest scale publicly available dataset on life expectancy.

I also consider several variables collected at the state level, beginning with infant mortality using data from the Wisconsin Department of Health Services (DHS) [32]. Wisconsin DHS publishes vital statistics reports annually, with the most recent infant mortality report following the 2017 birth cohort, for which deaths before age 1 were calculated the following calendar year. I consider childhood lead poisoning from the Wisconsin Childhood Lead Poisoning Prevention Program at Wisconsin DHS, which manages regular lead testing in children and reports case counts for young children $(<6$ years old) with 5 or more $\mu \mathrm{g} / \mathrm{dL}$, which is the CDC cut-off for poisoning. The most recent data at the census tract level are from 2013-2016.

Wisconsin DHS [33] also conducts the annual Wisconsin Behavioral Risk Factors Survey, which samples cell phone and landline telephones to survey residents about health conditions and behaviors. I accessed the Trend Data module for the years 2014-2016 to consider several health outcomes for whites, Blacks, and Hispanics at the county level, including asthma prevalence (respondents answered yes to "Have you ever been told by a health professional that you have asthma?" and "Do you still have asthma?"), diabetes prevalence (also self-reported, excluding women who only had gestational diabetes), self-reported general health status ("Would you say in general that your health is excellent, very good, good, fair, or poor?"), current smoking ("Do you now smoke cigarettes every day, some days, or not at all?"), exercise ("During the past month, other than your regular job, did you participate in any physical activities or exercise such as running, calisthenics, golf, gardening, or walking for exercise?"), and body mass index (BMI) (calculated with selfreported height and weight).

Finally, using data from the Wisconsin DHS [34] Electronic Disease Surveillance System, I track the monthly census tract distribution of COVID-19 cases for 6 months, beginning 1 month after the first presumptive case of COVID-19 was identified on March 13, 2020. I include cumulative positive case counts that are reported to DHS by all laboratories and health care providers, as well as percent positivity $^{2}$ (positive cases/total tests) for majority white, Black, and Hispanic census tracts. During those months, I include details of relevant events that potentially affected the spread of the disease, and I include mortality data by age and race from the Milwaukee County Medical Examiner's Office (2020) [35], including all confirmed and presumptive cases of COVID-19. I compare case and death rates by race and poverty and by race and high school education, and I compare 2020 death rates with "natural" deaths with the same causes listed for COVID-19 deaths (e.g., cardiovascular disease) for 2019 and 2018.

\section{Results}

Figure 1 shows Milwaukee County, Wisconsin census tracts with (a) majority white, Black, and Hispanic census tracts; (b) high poverty rates; and (c) low high school completion rates. The distribution of race at the census tract level reveals the segregated character of the county: The white neighborhoods extend along the shores of Lake Michigan and the southern and western suburbs. The near south neighborhoods are primarily Hispanic, with mixed-race neighborhoods on the edges. North of highway 94, spanning to the northwest, the tracts are primarily Black, with 20 census tracts more than $90 \%$ Black; several mixed-race tracts also sprinkle the edges of an otherwise unbroken series of Black neighborhoods. Poverty is most concentrated in the downtown areas where highways 43, 94, and 794 intersect, spanning out to the near south and northwest. The poorest census tract is 147 , just northwest of the major highway intersection, where $78.4 \%$ of households are below poverty; the five surrounding census tracts range from $52.1 \%$ to $63.5 \%$ of households in poverty.

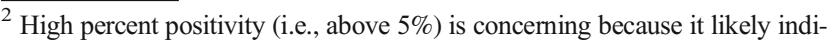
cates unmeasured community spread.

${ }^{3}$ I include all "natural" deaths that include COVID-19 as the primary cause, as well as an additional 69 deaths (16\%) that include COVID-19 as a secondary cause. Notably, the number of non-COVID-19 natural deaths in 2020 (excluding alcohol-related deaths, cancers, and genetic conditions) is similar to the numbers of deaths in previous years (see Fig. 4), making the 489 COVID-19 deaths appear to be "excess deaths."
} 
(a) Race

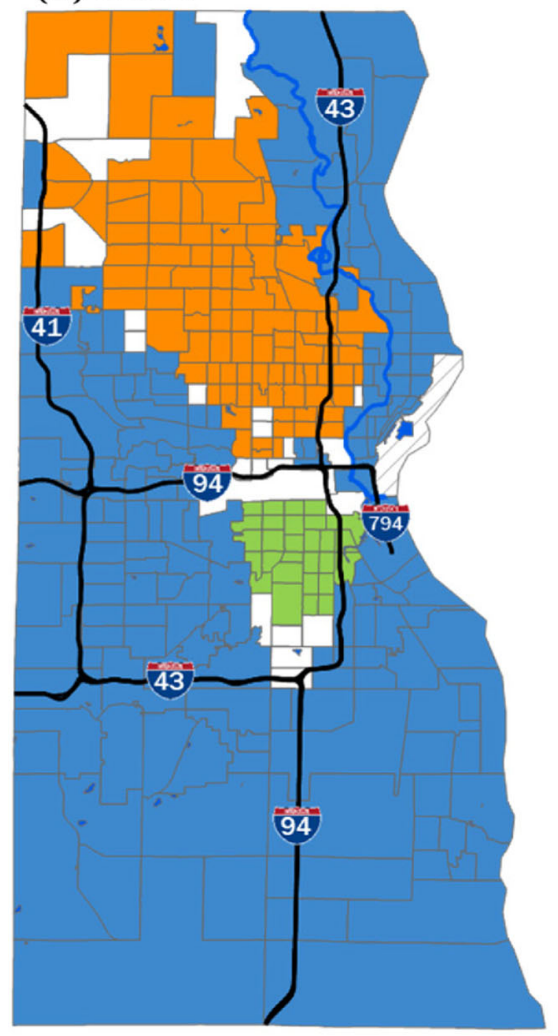

White $\square$ Black $\square$ Hispanic (b) Poverty

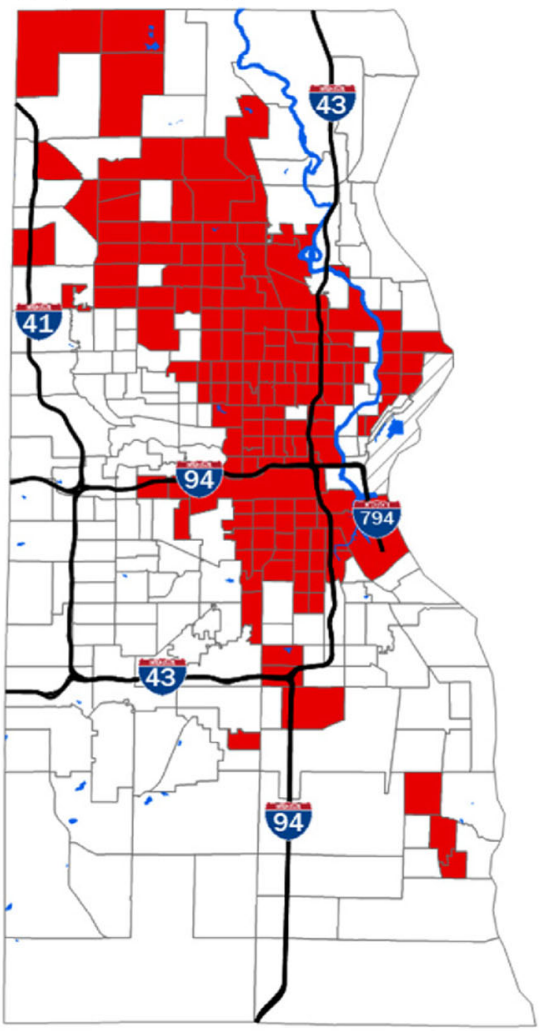

High poverty rates (c) High school

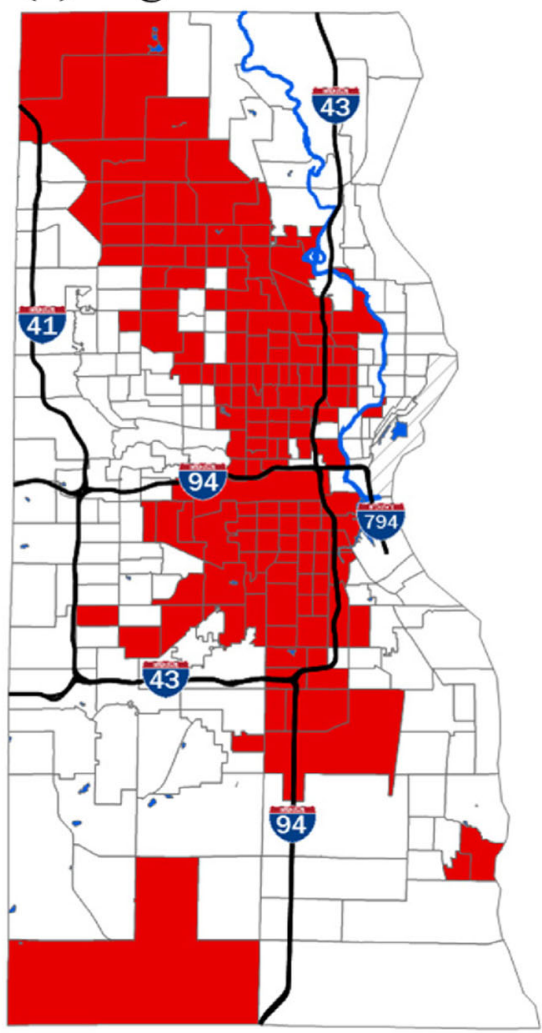

Low HS completion rates

Fig. 1 Milwaukee County, Wisconsin census tracts with a majority white, Black, and Hispanic residents; b high poverty rates; and $\mathbf{c}$ low high school completion rates

The mixed-race tracts are primarily below the median poverty rate. Lack of education is similarly distributed, with the tracts with the highest percentage of $25+$ year olds with no high school degree clustered in the near south neighborhoods. Tract 167 is the least educated in the county, with $58.6 \%$ of $25+$ year olds having no high school degree. The seven neighboring tracts range from $35.6 \%$ to $45.4 \%$ of $25+$ year olds with no high school degree. The lack of education fans to the north and northwest, though only one tract north of highway 94 exceeds $40 \%$ with no high school degree. Only a small number of majority white tracts have high poverty or low education; they include several tracts to the southeast, and the southwestern-most tract.

The Black neighborhoods display the worst outcomes. Life expectancy, for example, while unavailable in $20 \%$ of tracts, largely follows the same race and socioeconomic status (SES) patterns: the lowest rates occur to the north and northwest, with newborns commonly expected to die before age 70 . Majority Black tracts have an average life expectancy of 73.3, whereas the average life expectancy of majority white tracts is 78.3 and that of Hispanic tracts is 75.5 (the state average is 79.6). Tracts with more than the median household poverty rate $(18.8 \%)$ have an average life expectancy of 74.1, compared to 78.6 for tracts with less poverty, and tracts above the median percentage of 25+ year old adults with no high school degree $(11.3 \%)$ have an average life expectancy of 74.6 , compared to 78.6 for those that are relatively more educated.

Infant mortality is also worst for Blacks. For the years 2016, 2017, and 2018, the infant mortality rates were 14.6/ 1000 births for Blacks, 6.3/1000 for Hispanics, and 4.8/1000 for non-Hispanic whites. For infants from mothers with less than a high school degree, the overall rate was 9.1/1000 (vs. 3.6/1000 for college graduates and higher), and it was 19.1/ 1000 for Blacks, 5.3/1000 for Hispanics, and 7.3/1000 for whites. With a high school degree, the rate for Blacks only drops to $13.8 / 1000$, and with a college degree or higher, the rate is $6.8 / 1000$.

Lead exposure data from 2013-2016 indicate worse exposure for Black tracts, when majority Black tracts had four times as many cases of childhood lead exposure than nonBlack tracts, and more than seven times that of majority white tracts. Hispanic tracts had over five times the rate of white tracts.

The Behavioral Risk Factor Survey (2014-2016) indicates differences in several relevant health outcomes: asthma rates are higher for Blacks (19.4\%) than for Hispanics (13.4\%) or whites $(10.1 \%)$, and diabetes rates are higher for Blacks 
$(13.2 \%)$ than for whites $(8.9 \%)$ or Hispanics $(4.8 \%)$. Black respondents also have higher rates of judging their health as fair/poor $(30.2 \%)$ than Hispanics $(28.1 \%)$ or whites $(14.0 \%)$. Finally, behavioral factors are worse for Blacks for current smoking (Blacks: 31.9\%; whites: 15.3\%; Hispanics: 11.8\%), no exercise (Blacks: 36.1\%; Hispanics: 28.8\%; whites: $17.5 \%$ ), and obesity (Blacks: $39.5 \%$; Hispanics: $30.7 \%$, and whites: $29.8 \%$ ).

\section{COVID-19}

March 13, 2020. The first presumptive case of COVID-19 in Milwaukee County is announced by the City of Milwaukee Health Department.

March 24. The Wisconsin Department of Health Services issues the Safer at Home Order, ordering residents to primarily stay at home, although "essential" operations (e.g., transportation and grocery workers) are exempted.

March 27. The Coronavirus Aid, Relief, and Economic Security Act (CARES Act) is signed by President Trump. Single adults are provided with a $\$ 1200$ stimulus, and $\$ 600$ per week is added to unemployment benefits.

April 6. With news of poll workers in short supply for the April 7 Spring Election, and the state legislature refusing to discuss an all-mail election, Governor Tony Evers issues an Executive Order suspending in-person voting for April 7. Later in the day, the State Supreme Court cancels the Executive Order (Wisconsin Legislature v. Evers). The U.S. Supreme Court rules in opposition to extending the deadline for absentee voting.

April 7. The election occurs. In Milwaukee, there are five polling sites compared to the typical 180 . Long lines are reported at polling sites, with 18,800 Milwaukee residents showing up in-person [36].

April 13. One month since the first case was reported, Milwaukee County has had 1743 confirmed cases and 95 deaths. Majority Black census tracts have positive rates of $2.5 / 1000$ cases, compared to $0.7 / 1000$ for white tracts and 1.3/1000 for Hispanic tracts (see Fig. 3a), but percent positivity has far exceeded the $5 \%$ cutoff indicating substantial unmeasured community spread, with values of $18.6 \%$ for Black tracts, $6.9 \%$ for white tracts, and $13.5 \%$ for Hispanic tracts (see Fig. 3b).

May 13. The Wisconsin Supreme Court nullifies the Safer at Home Order, making it unenforceable.

Two months since the first case was reported, Milwaukee County has had 4215 confirmed cases and 236 confirmed deaths. The whitening in Fig. 2a shows case rates exceeding $5 / 1000$ and at times $10 / 1000$ in census tracts that mostly include the Hispanic and Black neighborhoods, with the highest rate (20.4/1000 cases), in predominantly white West Allis, as an exception. Majority Black census tracts have positive rates of 5.7/1000 cases, compared to 2.4/1000 for white tracts and 9.1/1000 for Hispanic tracts (Fig. 3a). Percent positivity values have dropped slightly to $14.5 \%$ for majority Black tracts, risen to $10.1 \%$ for majority white tracts, and more than doubled to $29.8 \%$ for majority Hispanic tracts (Fig. 3b).

May 25. The daytime murder-by-police of George Floyd, 335 miles west of Milwaukee, is shared with the world on cellphone video.

May 27. At least 100,000 COVID-19 deaths have been reported in the U.S.

May 29. Protests over Floyd's death begin in Milwaukee, with looting and confrontations with the police.

June 13. Three months since the first case was reported, Milwaukee County has had 9418 confirmed cases and 350 confirmed deaths. Majority Black census tracts have positive rates of 9.8/1000 cases, compared to 5.4/1000 for white tracts and 32.0/1000 for Hispanic tracts (Fig. 3a). Percent positivity has dropped for all groups but remains over $20 \%$ for Hispanic tracts, and above $5 \%$ for Black and white tracts (Fig. 3b).

June 19. This historic day, known as Juneteenth, marks a celebration of the ending of slavery. It has become a day of reflection over centuries of brutal oppression, subjugation, and incessant discrimination of African Americans. Protests around the world have taken precedence over stay-at-home and social distancing orders and guidelines.

July 13. Four months since the first case was reported, Milwaukee County has had 14,098 confirmed cases and 398 confirmed deaths. Majority Black census tracts have positive rates of $15.1 / 1000$ cases, compared to $9.3 / 1000$ for white tracts and 41.8/1000 for Hispanic tracts. Figure $2 \mathrm{~b}$ shows the yellowing of Black tracts to the north (e.g., 10+/1000 cases) and the reddening of many Hispanic tracts (e.g., 40+/1000 cases). The remaining tracts with very low case counts are primarily in white neighborhoods along Lake Michigan.

July 30. Governor Evers signs an Executive Order requiring the use of face coverings in public enclosed spaces.

July 31. The $\$ 600$ in supplemental unemployment benefits under the CARES Act expires.

August 13. Five months since the first case was reported, Milwaukee County has had 21,666 confirmed cases and 462 confirmed deaths. Majority Black census tracts have positive rates of $21.5 / 1000$ cases, compared to $16.5 / 1000$ for white tracts and 53.6/1000 for Hispanic tracts (Fig. 3a).

August 23. In Kenosha, Wisconsin, about 40 miles south of Milwaukee, Jacob Blake is shot seven times in the back by police. A video is released of Blake, who is Black, walking to the driver's side door of his vehicle as an officer follows, grabs his shirt, and begins firing. Blake's children are in the back seat.

August 24. Widespread protests are organized in Kenosha and elsewhere in Wisconsin, and some include rioting, looting, and fires. The National Guard is called. 


\section{(a) May 13}

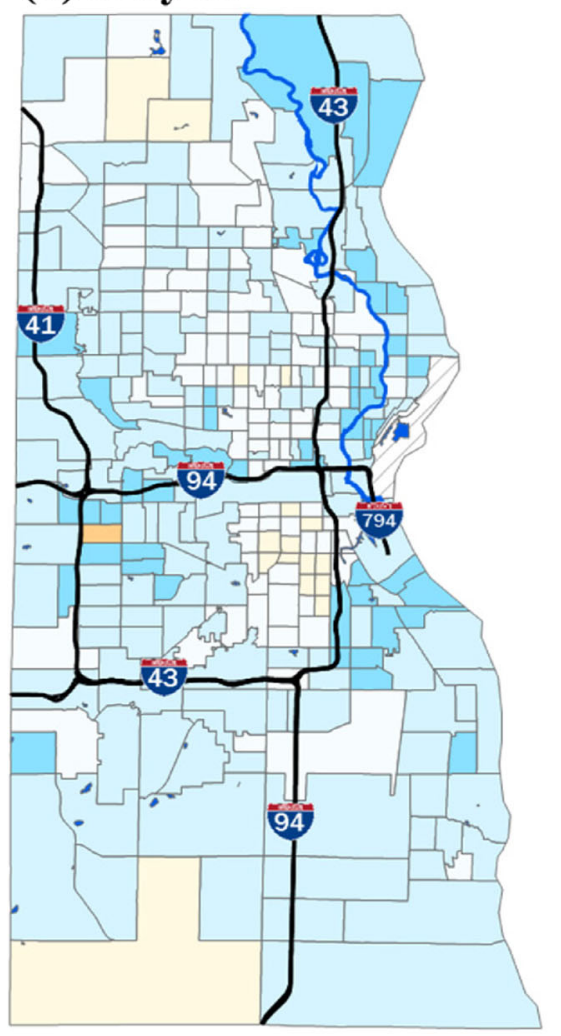

(b) July 13

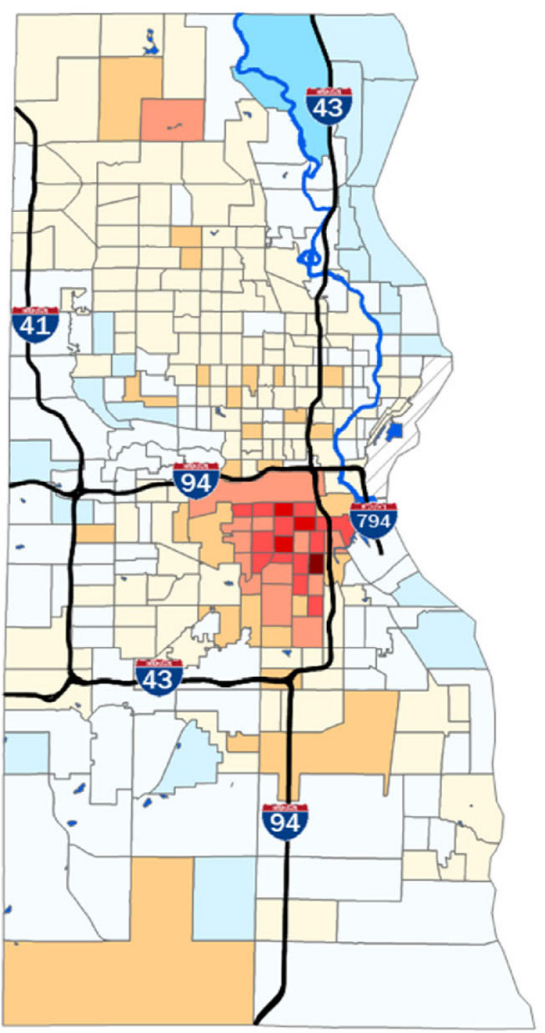

(c) September 13

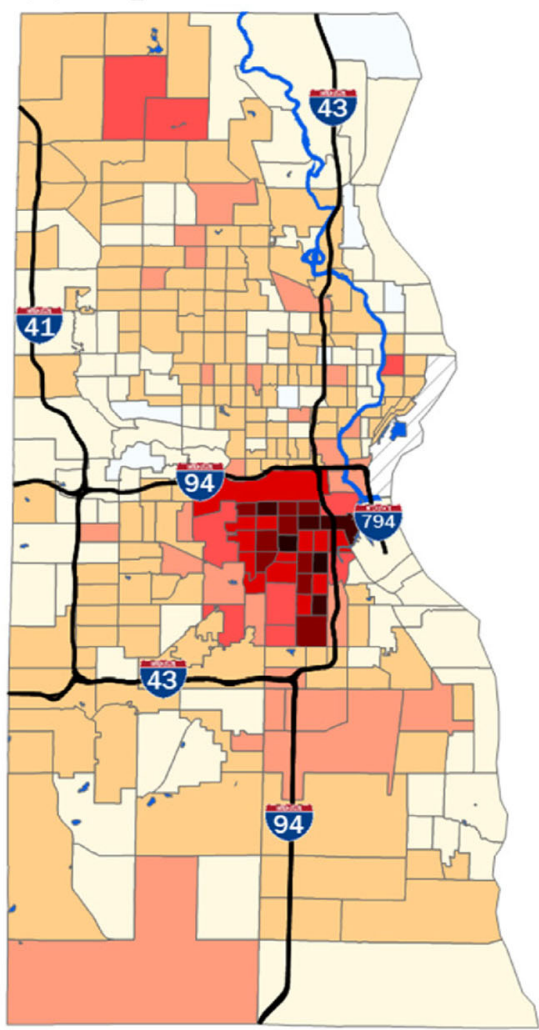

\section{Cases/1000}

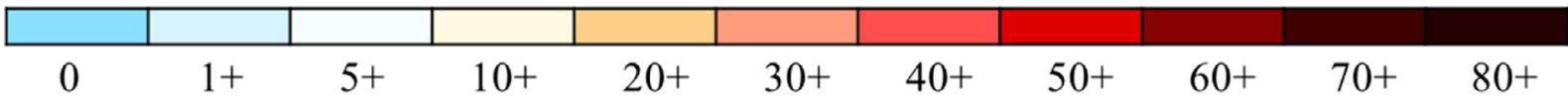

Fig. 2 Cumulative confirmed positive COVID-19 cases/1000 residents on a May 13, b July 13, and c September 13 in Milwaukee County, Wisconsin census tracts, 2020

August 25. At night, with a curfew order in place, the police drive through the streets in armored military style vehicles, and one officer is shown on video thanking a group of armed civilians who claim to have organized to protect buildings and property from the protesters. The officer says on the intercom, "We appreciate you guys, we really do," and offers water bottles [37]. Later, a teenager with a semiautomatic weapon scuffles with several protesters. He kills two (a)

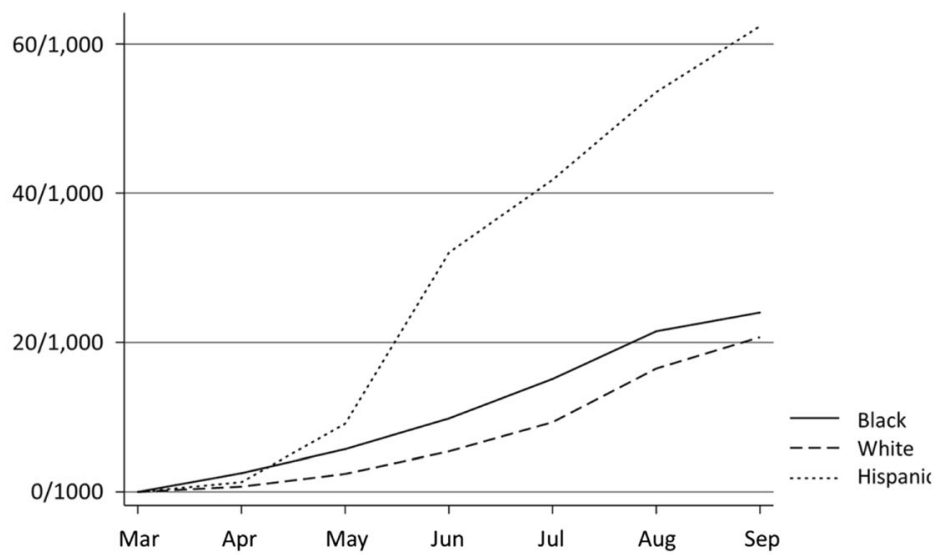

(b)

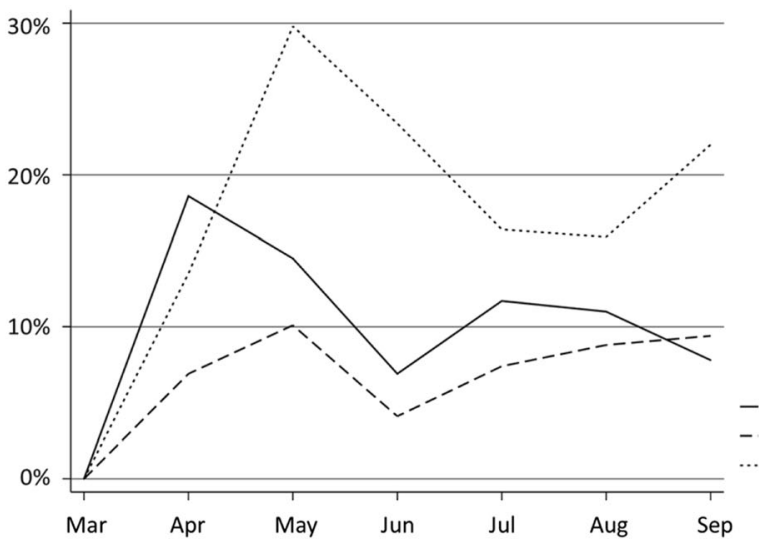

Fig. 3 a Monthly cumulative confirmed positive COVID-19 cases/1000 residents and b percent positivity for majority Black, white, and Hispanic census tracts in Milwaukee County, Wisconsin since the first case was reported on March 13, 2020 to September 13, 2020 
and wounds a third. At a news conference afterwards, the chief of police blames the deaths on people violating curfew.

August 26. President Donald Trump tweets that he is sending federal troops to Kenosha to "restore LAW and ORDER!"

September 4. The Centers for Disease Control and Prevention orders a "temporary halt" to residential evictions, noting that the rent will still be owed when the order expires on December 31. Qualifying tenants must complete and provide a form to their landlords to be protected.

September 13. Six months since the first case was reported, Milwaukee County has had 25,554 confirmed cases and 514 confirmed deaths. Majority Black census tracts have positive rates of 24.0/1000 cases, compared to 20.7/1000 for white tracts and 62.4/1000 for Hispanic tracts. Figure 2c shows that most tracts have turned orange (e.g., 20+/1000 cases), with low case tracts along Lake Michigan and in the western suburbs. Hispanic tracts stand out as increasingly dark shades of red, with blackish tracts reporting more than 80/1000 COVID19 cases. Percent positivity values have remained above 5\% for Black and white tracts, and have risen again above $20 \%$ for Hispanic tracts (Fig. 3b).

Table 1 shows total cases per 1000 individuals by majority race and poverty, and by majority race and high school completion. Among white, Hispanic, and no majority tracts, low poverty tracts display lower case rates and percent positivity compared to high poverty tracts; for Black tracts, case rates are higher and percent positivity is higher for low poverty compared to high poverty tracts. Likewise, for white and no majority tracts with high rates of high school completion (there are no Hispanic tracts), the case rates and percent positivity values are substantially lower, whereas for Black tracts, case rates are similar.
Figure 4 shows the monthly natural deaths between March 13 and September 13 for 2018, 2019, and 2020, with COVID-19 attributed deaths shown in addition to the other natural deaths in 2020. In 2020, there have been 489 COVID19 deaths, including 171 Black deaths, 229 white deaths, and 67 Hispanic deaths. Black deaths outnumbered white deaths early on in the pandemic but have been reduced every month since April, and Hispanic deaths have been reduced since June. White deaths increased substantially between July and August. The average age of COVID-19 deaths is 79.9 years for whites, 72.5 years for Blacks, and 61.3 years for Hispanics (Table 2). For each group, individuals who died from COVID19 were older, on average, than those who died of unrelated natural deaths, both for 2020 and for previous years. The age disparity ranges between 8.5 and 13.5 years, with COVID-19 deaths occurring in older individuals.

Table 2 also shows the percentage of total natural deaths by race for 2018, 2019, 2020, and for COVID-19. First, note that the county is $51.9 \%$ white, $26.1 \%$ Black, and $14.8 \%$ Hispanic. For whites, the share of natural deaths was typically higher than that of their share of the population (e.g., $64.8 \%$ of natural deaths in 2018 were white). Next, note the share of COVID-19 deaths: for whites, the share was $46.8 \%$ of deaths. The opposite was true for Blacks: in 2018, for example, 27.3\% of deaths were Black - similar to the share of Blacks in the population-whereas $35.0 \%$ of COVID-19 deaths were Black. The trend was most severe for Hispanics, where between $2.6 \%$ and $4.2 \%$ of natural deaths were Hispanic for 2018, 2019, and 2020, but $13.7 \%$ of COVID-19 deaths were Hispanic.

September 22. At least 200,000 COVID-19 deaths have been reported in the U.S.

Table 1 Cases of COVID-19 and percent positivity values on September 13, 2020 for Milwaukee County census tracts by majority race and poverty, and by majority race and high school completion

\begin{tabular}{|c|c|c|c|c|}
\hline & \multicolumn{2}{|c|}{ Low poverty ${ }^{\mathrm{a}}$} & \multicolumn{2}{|c|}{ High poverty } \\
\hline & Cases & Positivity & Cases & Positivity \\
\hline Over $50 \%$ Black & $27.2 / 1000$ & $11.1 \%$ & $23.7 / 1000$ & $10.6 \%$ \\
\hline Over $50 \%$ white & $20.1 / 1000$ & $7.9 \%$ & $23.9 / 1000$ & $9.9 \%$ \\
\hline Over 50\% Hispanic & $47.6 / 1000^{\mathrm{b}}$ & $15.9 \%^{\mathrm{b}}$ & $63.0 / 1000$ & $20.6 \%$ \\
\hline \multirow[t]{2}{*}{ No majority } & $28.5 / 1000$ & $11.4 \%$ & $32.9 / 1000$ & $11.9 \%$ \\
\hline & \multicolumn{2}{|c|}{ High high school completion ${ }^{c}$} & \multicolumn{2}{|c|}{ Low high school completion } \\
\hline Over 50\% Black & $24.1 / 1000$ & $10.5 \%$ & $24.0 / 1000$ & $10.7 \%$ \\
\hline Over $50 \%$ white & $19.1 / 1000$ & $7.6 \%$ & $29.7 / 1000$ & $12.0 \%$ \\
\hline Over $50 \%$ Hispanic & No tracts & No tracts & $62.4 / 1000$ & $20.4 \%$ \\
\hline No majority & $19.6 / 1000$ & $8.9 \%$ & $33.7 / 1000$ & $12.3 \%$ \\
\hline
\end{tabular}

${ }^{\text {a }}$ Below the median percentage of households below poverty (18.8\%)

${ }^{\mathbf{b}}$ One tract

${ }^{\mathbf{c}}$ Below the median percentage of $25+$ year olds with no high school degree (11.3\%) 
Table 2 Average age and percentage share of total natural deaths for the same period of COVID-19 surveillance, March 13 to September 13, in 2018, 2019, and 2020, Milwaukee County, Wisconsin

\begin{tabular}{llllll}
\hline & $2018: 330$ deaths & 2019: 351 deaths & 2020: 290 deaths & COVID-19: 489 deaths \\
\hline Black $^{\mathrm{a}}$ & Age & 59.0 & 59.2 & 64.5 & 72.5 \\
& Percent of total & $27.3 \%$ & $27.4 \%$ & $31.7 \%$ & $35.0 \%$ \\
\multirow{2}{*}{ White } & Age & 68.1 & 66.8 & 71.4 & 79.9 \\
& Percent of total & $64.8 \%$ & $67.0 \%$ & $61.7 \%$ & $46.8 \%$ \\
Hispanic & Age & 58.9 & 51.6 & 58.2 & 61.3 \\
& Percent of total & $4.2 \%$ & $2.6 \%$ & $3.1 \%$ & $13.7 \%$ \\
\hline
\end{tabular}

${ }^{\text {a }}$ Milwaukee County is $26.1 \%$ Black, $51.9 \%$ white, and $14.8 \%$ Hispanic

\section{Discussion}

To be sure, the year 2020 will be remembered for the COVID19 pandemic, but the context of various social and political events is relevant to the health disparities that continue to develop. To some, the Black Lives Matter protests, as well as the counterprotests, may have seemed products of pandemic life and economic strife. To others, they may have seemed products of the Trump era, with race-based politics temporarily taking a national stage from two groups that simply felt left behind. Yet from a historical perspective, these dynamics are as old as the Milwaukee neighborhood, when newcomers were relegated to single rooms in the older houses as the longtime residents moved away for more space, better views, and the safety of SES and ethnic homogeneity.

Race-based angst in Milwaukee has no doubt existed since the first white settlers arrived to find an indigenous population in their way, but the arrival of tens of thousands of Southern Blacks in the 1940s through the 1960s created a city with strict race lines and extreme intractable poverty, with affluent people in the suburbs feeling it unjust that their well-earned money would be used to solve the problem. Then, with manufacturing jobs leaving the county en masse, it is no wonder that many voters would be receptive to blaming the unions for their own misfortune, especially in the context of public employees supposedly faring so well. At the same time, African American residents had lifetimes of living with some of the worst disparities of almost any group worldwide. Their persistent troubles cannot be separated from the history of slavery, and the centuries of disenfranchisement, discrimination, and persecution that, at one time explicit and ubiquitous, have seeped into daily life in the U.S., resulting in segregation and unfair housing practices, institutional racism throughout the criminal justice system, job market and workplace biases, disadvantageous educational reforms and practices, and even detrimental medical practices (see [38]).

And yet, it is troubling that a global pandemic - itself indifferent to race and class - would arrive and affect these groups so differently, and so predictably. As is often the case, high-SES residents tend to be the most insulated from the events. For example, the percentage share of total natural deaths for whites was approximately 65\% in 2018 and 2019, whereas whites were the only group whose share of COVID19 deaths dropped, and by over $25 \%$. Furthermore, their average age of death from COVID-19 was 79.9, where many of the deaths were the oldest old - the population with the highest risk of death from COVID-19. So why such differences? Possibly because many of the younger white populations are
Fig. 4 Monthly "natural" deaths for the same period of COVID-19 surveillance, March 13 to September 13, for 2018 (dotted), 2019 (dashed), and 2020 (solid), with COVID-19 attributed deaths shown in shaded areas

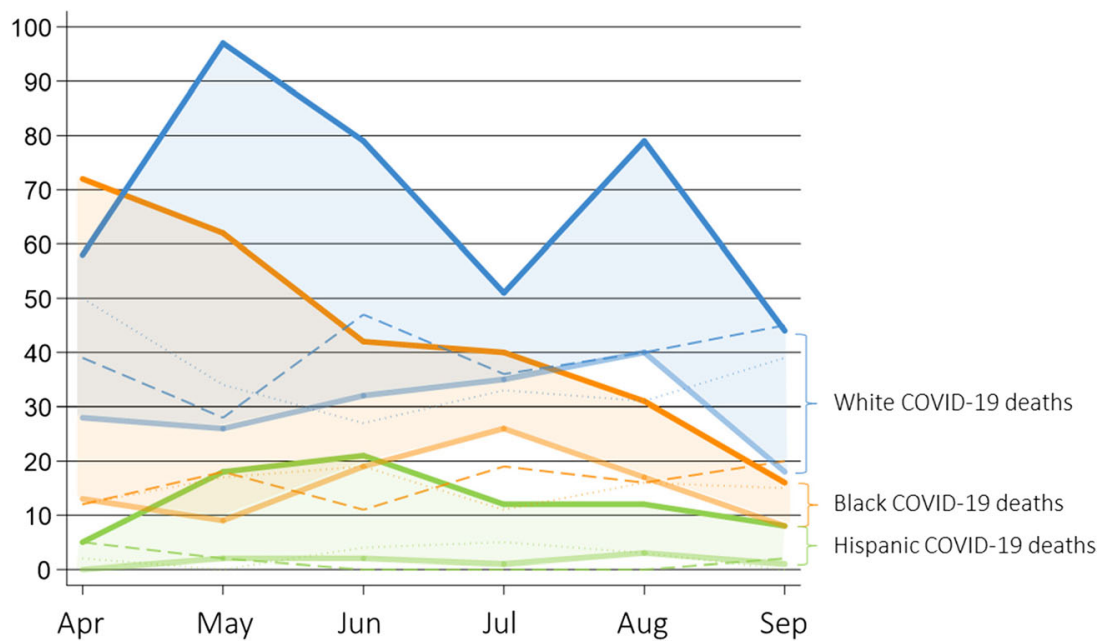


protected for all-too-obvious reasons: amenities at home, money for home exercise equipment, and support to work from home even if a child or two is occasionally visible in a Zoom meeting. These high-SES residents live in a different universe than many of those in north or near south Milwaukee, where the hope of a stimulus payment, or the fear of COVID19 , may be dampened by overdue bills, lost wages, and eviction.

Percent positivity is another indicator of expected differences among the three groups: the rate for white tracts barely reached $10 \%$ in May and then dropped well below in other months, whereas the Black tract rates were higher but primarily followed the same trend; the Hispanic tracts spiked to nearly $30 \%$ in May, dropped below $20 \%$ in July and August, but were on the way back up in September. By indicating the unmeasured community spread, these disparities show that the Hispanic communities, and to a lesser extent the Black communities, are not seeking treatment to the extent that the white communities are.

In Milwaukee, the highly segregated poor Black communities to the north and northwest experience the worst outcomes in terms of life expectancy, lead exposure, infant mortality, asthma, and diabetes, and they have higher rates of obesity, smoking, and no exercise. It has yet to be seen how these existing disparities will be exacerbated by COVID-19, although existing patterns may provide a clue: in a hospital system in northern California, African American patients had 2.7 times the odds of hospitalization with COVID-19 compared to white patients [39]. In Milwaukee County, Blacks have a greater share of COVID-19 deaths, especially when their relatively low share of "natural" deaths in the past is taken into account, and especially given that the overall case rates are relatively similar between Black and white majority census tracts. On top of this, the average age of death is 7.4 years younger for Blacks than for whites, which in part reflects a younger median age but also suggests that the disparities between white and Black would be even greater if the Black population were more similar (see [40]). So, does COVID-19 impact Black patients more severely than white patients? Given the historical context, it is difficult to imagine how it could not.

While high unemployment in the Black communities may provide a perverse protection from COVID-19 exposure, the employed are more likely to work in the service sector and rely on public transportation, where the risk of infection is higher (see [41]). Furthermore, segregation, incarceration, and the accompanying social disorder may worsen the illness course when it arrives [42], which may be confounded by delays in treatment that stem from healthcare inequities and longstanding distrust in medical authority. ${ }^{4}$

\footnotetext{
4 The Tuskegee Syphilis Study, when hundreds of African American men were denied treatment for syphilis to study the course of the disease, is but one source of African American distrust in medical authority (see [43]).
}

The Hispanic communities in the near south are severely impacted by COVID-19 as well, with case rates approaching 1 out of 10 residents in many neighborhoods. Thus far, however, the share of COVID-19 deaths appears to be relatively low given the high percentage of positive cases. For the period in question, the Hispanic share of COVID-19 deaths is $13.7 \%$, which is striking compared to the $2.6 \%-4.2 \%$ share of "natural" deaths in past years but still indicative of a lower mortality rate than whites or Blacks. It seems likely that Hispanics with COVID-19 are younger on average than other groups with the disease; consistent with this notion, the average age of death is 18.6 years younger for Hispanics than for whites. Are older individuals in these communities eventually going to increase the average age of death? Are Hispanics somewhat insulated from the disease because of behavioral factors? It is curious that these slightly positive outcomes, given the case counts, are consistent with research on the "Hispanic health paradox," where low SES Hispanic (and especially Mexican) immigrants have much better health outcomes than would be expected by their circumstances [44]. Of course, much of Milwaukee's Mexican population is young, first-generation U.S., so it is possible that in addition to a lower risk profile for COVID-19, behavioral patterns such as lower incidences of smoking (see [45]) may provide insulating effects.

It is also possible that the high rates of infection in the Hispanic neighborhoods are simply driven by occupation trends, with spread coming from relatively young workers becoming infected after taking public transportation or working in small groups where social distancing and mask wearing are not possible or normalized. Although, are there really so few older adults at home, vulnerable to becoming sick from their working grandchildren?

In part because the Hispanic communities in Milwaukee have such low high school completion rates, the disease overall appears to affect the under-educated the most. However, education does not appear to insulate Black communities, and nor does income: Black tracts with low poverty fare worse in cases and percent positivity than white tracts with high poverty. In fact, Black tracts fare worse in low versus high poverty, and they fare no better in high versus low high school completion rates. This is not the case for white tracts: low poverty and high education, to some extent, appear to insulate white neighborhoods from COVID-19. The same protection occurs for mixed-race tracts and for Hispanic tracts for low poverty. One way of thinking about this is that education and income do not have the same protective effect for Black communities as they do for other communities, potentially suggesting that the causes of the disparities are primarily related to race rather than SES.

During Jane Addams's time, sickness and disease disproportionately impacted immigrant communities - primarily Polish and German - in the near south neighborhoods of Milwaukee; today, those same neighborhoods continue to 
receive the brunt of negative outcomes, although it is now Hispanic (primarily Mexican and Mexican American) communities in the old Polish flats. In some tracts, case rates are approximately 4.5 times the rate of majority white tracts, with many more likely unreported. Perhaps unsurprisingly, many of the white neighborhoods that have been most affected south and southeast of the old Polish flats, as well as in West Attis, are where the Polish and German immigrants moved in the early and mid-century - the same ones who suffered worst when they arrived over a century ago. It appears that those communities still have not caught up to the affluent whites who were most insulated back then.

The situation for all people of color may worsen before it improves. The U.S. Bureau of Labor Statistics shows dire numbers that also reveal disparities by race: the September 2020 unemployment estimates are $7.0 \%$ for whites, $12.1 \%$ for Blacks, and $10.3 \%$ for Hispanics. Other estimates [46] suggest the unemployment rate for Hispanics is even worse, and the end of COVID-19 remains out of sight, with supplemental unemployment benefits currently stopped, the end of the eviction moratorium arriving at the end of the year, and low wage jobs impacted the most.

It remains unknown how many people will be unable to pay their rents and mortgages, and who will be evicted or lose their homes, but history suggests the disparities will persist in communities for generations. In the meantime, case numbers are on their way back up.

\section{Conclusion}

The winter of 1895, an especially cold one in Chicago, marked a low point in the life of Jane Addams. The U.S. was in a severe depression, she was fighting Typhoid fever, her oldest sister had recently died, and her professional efforts seemed futile.

Her professional disillusionment centered on industrialist George Pullman. In the 1880s, he had built a utopian town for his railroad workers, receiving international acclaim for his paternalistic benevolence [47]. The town kept the workers out of the tenement slums, presumably serving everyone's interest, not least of which included the employer-turned-landlord, who used his political clout to price gouge the cost of rent, gas, water, and even library membership [48]. Then with the depression, Pullman focused on his bottom line, laying off workers, cutting others' wages, but maintaining rents and other bills for his employee tenants [49]. Some workers were literally starving, and in May of 1894, after a group of them were threatened with their jobs after they complained to Pullman about their plight, they went on strike.

The strike spread to include the American Railway Union, and Pullman doubled down, unwilling to negotiate. Addams tried to intervene, first by meeting with the families, who retained faith in Pullman, optimistic that their "straw boss" union leaders would easily be able solve the problem. She contacted Pullman, who ignored her. The American Railway Union leader urged the workers to remain peaceful - and they mostly did - but at times the crowds of subjugated workers turned riotous, even starting buildings on fire. Then, on July 4, against the explicit protests of the governor, President Grover Cleveland sent federal troops to Chicago to quash the unrest, convinced of a conspiracy to halt the national railway system [50]. Upon seeing thousands of federal troops, the strikers barricaded themselves in the railyards and began burning railcars. On July 6, a security guard shot two protestors, creating even more anger from the workers. In the subsequent days, Chicago looked like a war zone, and 11 more rioting protestors were killed. The protests and strikes spread nationally, and President Cleveland dispatched troops throughout the West, authorizing them to use deadly force as necessary. The union leader in Chicago urged calm, but many of the rioters were not even affiliated with the railroads [50]. Over 50 protesters were killed before calm returned, with national newspapers and much of the general public siding with the railroads and demonizing the union leader, who was later jailed, and likening him to a confederate anarchist. In the end, some workers were allowed to return to work, albeit only by committing to never unionize. Addams was friends with many of the workers and union leaders, seeing how their lives were ruined, some of them blacklisted from work and having mental breakdowns. Among other things, she felt shame for her own privilege, and ineffectual in her philanthropic pursuits [8].

In July 1896, Addams traveled to Russia to visit Leo Tolstoy, who, after rejecting his literary fame, had committed to living a peasant's life, believing that the only way to serve the poor was to live as one of them. Addams hoped for inspiration from the man, as she believed he epitomized "the ability to lift his life to the level of his conscience, to translate his theories into action" ( [8], pp. 259-280). Upon meeting him, Addams reported that Tolstoy became distracted by her flowery dress and pointed out that one sleeve alone could make a dress for a peasant girl. He asked whether she found the dress to be a "barrier to the people." Flustered, she attempted to respond that the working women in Chicago wore even bigger dresses, and that wearing a more efficiently trimmed dress would be the best way to separate herself from the people, and that even if she did want to dress like a peasant, as he did, "it would have been hard to choose which peasant among the thirty-six nationalities we had recently counted in our ward." Later, upon hearing that the Hull House relied on a farm well outside of Chicago, he replied, "So you are an absentee landlord? Do you think you will help the people more by adding yourself to the crowded city than you would by tilling your own soil?" 
That night, eating only porridge and black bread, Tolstoy expressed remorse at the fortune of a Russian spy who, under a ruse, had recently visited to obtain a copy of his forbidden manuscript, "Life"; Tolstoy had unwittingly convinced the spy of his views, and the spy had confessed to the authorities, receiving a punishment of exile. Tolstoy was troubled by the outcome, believing it a shameful misuse of force from the Russian authorities. Here Addams's view is most prescient: "he made too great a distinction between the use of physical force and that moral energy which can override another's differences and scruples with equal ruthlessness." Like the railroad baron, the union leader, the scholar, Addams saw moral certainty as a barrier to social justice, which necessarily involved sympathy, humility, and compromise.

Addams was bothered by her own disagreement with Tolstoy, no resolution in sight to her feelings of futility. She even pledged on her long journey home to spend part of every morning working in the Hull House bakery, hoping to contribute to a peasant's work, perhaps finding some redemption in the process. Her father, after all, had required all of his daughters to bake a perfect loaf for him on each of their twelfth birthdays, so however inconvenient it might be for the German union baker, she would be returning to her roots. She fantasized about it the whole way home.

Then, on her first morning back at the Hull House, with a line of people waiting to see her, with piles of unopened letters, she asked herself, "Were these all to be pushed aside and asked to wait while I saved my soul by 2 hours work at baking bread?" Of course not, she decided in that moment, and then she got back to work.

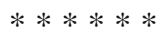

In the time of COVID-19, these times may stoke our angst about moral and social injustice, and about the roles we want to play. There has never been a better time, perhaps, to remember Jane Addams, and to reflect on the roots of pragmatist thought: for Addams, our moral responsibility is to resist the temptation to "narrow our frame of reference in order to pretend toward neutrality," as Lake [51] puts it.

On one hand, this means being aware of social problems, including the social determinants that so fervently impact the health of poor people and people of color. On the other, it means avoiding the temptation to solve problems by fanning our moral certitude. Rather, we should aim for "sympathetic understanding" of what may appear to be the other side. For Addams, this meant seeing social problems with apparent good and bad actors as "perplexities" rather than problems with right and wrong ( [51]; see also [52]).

In this time of political antagonism, as social inequality continues its insidious spread, as we wait impatiently in our homes for all of this to end, we are certainly challenged.

Such is life in the time of COVID-19.
Acknowledgements The author would like to acknowledge the peerreviewers as well as individuals who commented on early versions of the manuscript.

Authors' Information Department of Occupational Therapy, Lewis School of Health Sciences, Clarkson University, 8 Clarkson Ave, Potsdam, NY 13699, U.S.

David Schelly

Availability of Data and Materials The data that support the findings of this study are available in the public domain.

Authors' Contributions DS competed all work on this study and manuscript.

\section{Declarations}

Ethical Approval and Consent to Participate Ethical approval was not required because all data were available in the public domain.

Consent for Publication DS consents to publication of this work.

Competing Interests The author declares no competing interests.

\section{References}

1. Link BG, Phelan J. Social conditions as fundamental causes of disease. J Health Soc Behav. 1995;35:80-94. https://doi.org/10. 2307/2626958.

2. Phelan JC, Link BG, Tehranifar P. Social conditions as fundamental causes of health inequalities: theory, evidence, and policy implications. J Health Soc Behav. 2010;51(1):S28-40. https://doi.org/ $10.1177 / 0022146510383498$.

3. World Health Organization. Social determinants of health; 2020. Retrieved from: https://www.who.int/social_determinants/ sdh definition/en/

4. Burström B, Tao W. Social determinants of health and inequalities in COVID-19. Eur J Pub Health. 2020;30(4):617-8. https://doi.org/ 10.1093/eurpub/ckaa095.

5. Biernacki J. The essential toxic symptoms of diphtheria. Br Med J. 1899;2(2035):1787-8.

6. Leavitt JW. The healthiest city: Milwaukee and the politics of health reform. Madison, WI: University of Wisconsin Press; 1996.

7. Omram AR. The epidemiologic transition: a theory of the epidemiology of population change. The Milbank Memorial Fund Quarterly. 1971;49(4):509-38. https://doi.org/10.2307/3349375.

8. Addams J. Twenty years at Hull House. Chicago: Hull-House; 1910.

9. Deegan MJ. Jane Addams and the men of the Chicago School, 1892-1918. Transaction Publishers; 1988.

10. Hunter R, Blaine AM, Addams J, McCormick C, Le Moyne LV, Bicknell EP. Tenement conditions in Chicago. City Homes Association; 1901.

11. Gavett TW. Development of the labor movement in Milwaukee. University of Wisconsin Press; 1965.

12. Anderson M, Greene V. Perspectives on Milwaukee's Past. University of Illinois Press; 2009.

13. Jones PD. The Selma of the North: civil rights insurgency in Milwaukee. Harvard University Press; 2009. 
14. Gurda J. Milwaukee: a City of Neighborhoods. Historic Milwaukee, Inc; 2015.

15. Trotter JW. Black Milwaukee: the making of an industrial proletariat, 1915-45. University of Illinois Press; 1985.

16. González S. Mexicans in Wisconsin. Wisconsin Historical Society Press; 2017.

17. Rodriguez JA, Sava W. Latinos in Milwaukee. Arcadia Publishing; 2006.

18. Gurda J. The making of Milwaukee. University of Wisconsin Press; 2008.

19. Alanen AR, Eden JA. Main Street ready-made. State Historical Society of Wisconsin; 1987.

20. Smith KD. From socialism to racism: the politics of class and identity in postwar Milwaukee. Mich Hist Rev. 2003;29(1):7195. https://doi.org/10.2307/20174004

21. Geib P. From Mississippi to Milwaukee: a case study of the Southern Black migration to Milwaukee, 1940-1970. J Negro Hist. 1998;83(4):229-48. https://doi.org/10.2307/2649025.

22. Jackson KT. Crabgrass frontier: the suburbanization of the United States. Oxford University Press; 1985.

23. White SB, LePage J. Sister: an African American life in search of justice. University of Wisconsin Press; 2013.

24. Alexander M. The war on drugs and the new Jim Crow. Race Poverty Env. 2010;17:75-7.

25. Desmond M. Evicted: poverty and profit in the American city. New York: Broadway Books; 2016.

26. Levine MV. Milwaukee 53206: the Anatomy of Concentrated Disadvantage in an Inner City Neighborhood, 2000-2017. Milwaukee, WI: Center for Economic Development Publications; 2019. https://dc.uwm.edu/ced_pubs/48

27. Zaniewski KJ, Simmons JR. Divided Wisconsin: partisan spatial electoral realignment. Geography Teacher. 2016;13(3):128-33.

28. Stein J, Marley P. More than they bargained for: Scott Walker, unions, and the fight for Wisconsin. University of Wisconsin Press; 2013.

29. Malin MH. Sifting through the wreckage of the tsunami that hit public sector collective bargaining. Empl Rights Employ Policy J. 2012;16:533-57.

30. Lauck JK. Trump and the Midwest: the 2016 Presidential Election and the Avenues of Midwestern Historiography. Studies in Midwestern History. 2017;3(1):1.

31. National Center for Health Statistics. U.S. Small-Area Life Expectancy Estimates Project (USALEEP): Life Expectancy Estimates File for Milwaukee, 2010-2015. National Center for Health Statistics; 2018. Available from: https://www.cdc.gov/ nchs/nvss/usaleep/usaleep.html.

32. Wisconsin Department of Health Services (DHS). Wisconsin Interactive Statistics on Health (WISH) Query System; 2019a. Available from: https://www.dhs.wisconsin.gov/wish/index.htm

33. Wisconsin Department of Health Services (DHS). WISH Query: behavioral risk factor survey trend data - state, regions, counties; 2019b. Available from: https://www.dhs.wisconsin.gov/wish/brfs/ form.htm

34. Wisconsin Department of Health Services (DHS). COVID-19: Wisconsin cases. Wisconsin Electronic Disease Surveillance System (WEDSS); 2021. Available from: https://www.dhs. wisconsin.gov/covid-19/cases.htm
35. Milwaukee County Medical Examiner. Public Data: deaths in Milwaukee County under Medical Examiner's jurisdiction; 2020. Available at: https://county.milwaukee.gov/EN/MedicalExaminer/Public-Data

36. Herndon AW. Off to the polls with masks, gloves, sanitizer and fear. The New York Times, A23; 2020.

37. Partlow J, Stanley-Becker I. As clashes between armed groups and leftist protesters turn deadly, police face complaints of tolerating vigilantes. The Washington Post; 2020.

38. Sharkey P. Stuck in place: urban neighborhoods and the end of progress toward racial equality. University of Chicago Press; 2013.

39. Azar KMJ, Shen Z, Romanelli RJ, Lockhart SH, Smits K, Robinson $\mathrm{S}$, et al. Disparities in outcomes among COVID-19 patients in a large health care system in California. Health Aff. 2020;39(7):1-8. https://doi.org/10.1377/hlthaff.2020.00598.

40. Snowden LR, Graaf G. COVID-19, social determinants past, present, and future, and African Americans health. J Racial Ethn Health Disparities. 2021;8(1):12-20. https://doi.org/10.1007/s40615-02000923-3.

41. Fletcher FE, Allen S, Vickers SM, Beavers T, Hamlin CM, YoungFoster D, et al. COVID-19's impact on the African American community: a stakeholder engagement approach to increase public awareness through virtual town halls. Health Equity. 2020;4(1): 320-5. https://doi.org/10.1089/heq.2020.0029.

42. Escobar $\mathrm{G}, \mathrm{Sema} \mathrm{T}$. Incarceration weakens a community's immune system: mass incarceration and COVID-19 cases in Milwaukee. In: Preliminary results. Measures for Justice; 2020.

43. Gamble VN. Under the shadow of Tuskegee: African Americans and health care. Am J Public Health. 1997;87(11):1773-8. https:// doi.org/10.2105/AJPH.87.11.1773.

44. Zsembik BA, Fennell D. Ethnic variation in health and the determinants of health among Latinos. Soc Sci Med. 2005;61(1):53-63. https://doi.org/10.1016/j.socscimed.2004.11.040.

45. Fenelon A, Chinn JJ, Anderson RN. A comprehensive analysis of the mortality experience of Hispanic subgroups in the United States: variation by age, country of origin, and nativity. SSM Population Health. 2017;3:245-54. https://doi.org/10.1016/j. ssmph.2017.01.011.

46. Fairlie RW, Couch $\mathrm{K}, \mathrm{Xu} \mathrm{H}$. The impacts of COVID-19 on minority unemployment: first evidence from April 2020 cps microdata (No. w27246); 2020. National Bureau of Economic Research.

47. McMillan G. Keeping the conversation going: Jane Addams rhetorical strategies in A Modern Lear. Rhetor Soc Q. 2002;32(3):6175. https://doi.org/10.1080/02773940209391234.

48. Lindsey A. Paternalism and the Pullman strike. Am Hist Rev. 1939;44(2):272-89. https://doi.org/10.1086/ahr/44.2.272.

49. Addams J. A modern Lear. Survey. 1912;29(2):131-7.

50. Papke DR. The Pullman case: the clash of labor and capital in industrial America. University Press of Kansas; 1999.

51. Lake D. Jane Addams and wicked problems: putting the pragmatic method to use. Pluralist. 2014;9(3):77-94. https://doi.org/10.5406/ pluralist.9.3.0077.

52. Addams J. Democracy and social ethics. Macmillan \& Co., Ltd.; 1902.

Publisher's Note Springer Nature remains neutral with regard to jurisdictional claims in published maps and institutional affiliations. 